\title{
Current State and Future of Biologic Therapies in the Treatment of Asthma in Children
}

\author{
Elissa M. Abrams, MD, FRCPC, Allan B. Becker, MD, FRCPC, and Stanley J. Szefler, MD²
}

There is increasing recognition of phenotypic variability in pediatric asthma, providing the opportunity for a more personalized approach to therapy. Increasingly biologic therapies, in particular those targeting the "allergic" (or T helper 2) pathway, are being considered for children with severe asthma. However, there is a great deal of variability in the extent these biologic therapies have been studied in children, as well as efficacy of results thus far. The goal of this article is to review the mechanism of action, efficacy, and potential predictive and monitoring biomarkers of the biologic medications focusing on the pediatric population, in an effort to establish a more personalized approach to asthma in the pediatric population for the 21 st century.

Keywords: asthma, asthma medications, asthma biomarkers, biologic therapies

\section{Introduction}

A STHMA AFFECTS $\sim 8 \%$ of North Americans, with evidence of an increase in prevalence over the past decade. $^{1-3}$ It is estimated that 7.0 million children in the United States have asthma.

Many children with asthma have evidence of poor asthma control, defined based on symptom control, frequency and severity of exacerbations, and airflow limitation. ${ }^{4,5}$ In the United States, $57 \%$ of children with asthma had an asthma exacerbation in 2008; 209 children in the United States died from asthma in $2016 .^{6}$

Recently released survey data from the United States note that asthma carries a "significant economic burden" with an estimated cost of $\$ 81.9$ billion in 2013. The TENOR (Epidemiology and Natural History of Asthma: Outcomes and Treatment Regimens) observational study has noted significantly higher rates of direct and indirect healthcare utilization, including significantly more days of school/work missed $(P<0.001)$ due to poor asthma control compared with well-controlled asthmatic patients. ${ }^{8}$

In contrast to poorly controlled asthma, severe asthma is identified based on the necessity of high-dose inhaled corticosteroid (ICS) therapy and a second controller therapy in the previous year, or systemic corticosteroids for $50 \%$ of the year, to prevent asthma from being uncontrolled or that remains uncontrolled despite these medications. ${ }^{9}$ Despite optimization of all other factors, about 5\%-10\% of the asthmatic population continue to have severe asthma, accounting for $\sim 50 \%$ of asthma healthcare utilization in North America. 4

There is increasing recognition that asthma is an umbrella term for various phenotypes, and an understanding of these phenotypic differences may allow a more personalized treatment approach to the severe asthmatic. One of these phenotypic pathways is thought to be the type 2 pathway ( $T$ helper 2 Th2), or the "atopic" pathway, which involves immunoglobulin(Ig)-E production, and release of cytokines (including interleukin [IL]-4, IL-5, IL-13). Some of the biomarkers specific for the Th2 pathway include peripheral blood and sputum eosinophilia or bronchoalveolar eosinophil counts, fractional exhaled nitric oxide (FeNO) levels, and serum periostin levels. ${ }^{4,10}$

Biologic therapies are increasingly being considered in patients with severe asthma. There are now biologic therapies targeting several of the mediators of the Th2 pathway (IgE, IL4, IL5, IL13, and others) as well as the "danger signal" pathway (eg, thymic stromal lymphopoietin [TSLP]).

The goal of this review is to highlight the mechanism of action, efficacy, and predictive biomarkers for the biologic medications, highlighting the work done in the pediatric (age 18 and younger) population whenever possible.

Future understanding of the successes and limitations of these medications should also assist in the overall management of asthma and the design of new medications to address unmet needs. From the available literature, it is

\footnotetext{
${ }^{1}$ Section of Allergy and Clinical Immunology, Department of Pediatrics, University of Manitoba, Winnipeg, Canada.

${ }^{2}$ Department of Pediatrics, Section of Pulmonary Medicine, Breathing Institute, University of Colorado School of Medicine, Aurora, Colorado.
} 
becoming clear that these medications affect, to varying degrees, rate of exacerbations, pulmonary function, medication reduction, and overall symptom control. Although the data available are increasing in the adult population, it is extremely limited in the adolescent proportion of these studies and even more limited in those $<12$ years of age.

This review provides an overview of the information available for each medication currently approved with an emphasis on what is known in adolescents and children. We also indicate where potential predictive and monitoring biomarkers are available. Predictive biomarkers are those that permit an estimate of likelihood of a medication having a positive response. Biomarkers can also assist with monitoring response to offer an early indication of benefit for the intervention. A perspective on other medications on the horizon will also be included with the available information on ongoing studies.

\section{Biologic Therapies}

\section{Anti-IgE medications: omalizumab and ligelizumab}

Omalizumab and ligelizumab (in development) are both humanized anti-IgE monoclonal antibodies that bind circulating $\operatorname{IgE}$, causing decreased $\mathrm{IgE}$ levels, inhibition of $\mathrm{IgE}$ binding with its receptors, and downregulation of $\operatorname{IgE}$ receptors on mast cells, basophils and dendritic cells (Table 1). ${ }^{11}$ Omalizumab binds to free $\operatorname{IgE}$, but not to $\operatorname{IgE}$ bound to mast cells (which would, through cross-linking, result in allergic mediator release). This results in decreased release of inflammatory mediators related to the allergic response. In a phase 1 study, ligelizumab has been shown to be more potent at suppressing free $\operatorname{IgE}$ and $\operatorname{IgE}$ bound to mast cells and basophils than omalizumab. ${ }^{12}$

There have been several observational and randomized controlled trials on the use of omalizumab in the pediatric population. In contrast, the data on ligelizumab are limited to a single phase 2 study in adults.

Omalizumab. Omalizumab is the only biologic therapy for asthma to be studied in children as young as 5 years of age and one of the only biologic therapies for asthma approved for pediatric use in children 6 years and older. There have been 2 observational studies ${ }^{13,14}$ and 4 randomized double blind placebo-controlled trials (RDBPCTs) ${ }^{15-18}$ of omalizumab in the pediatric asthmatic population (Figs. 1, and 2). All the studies but one ${ }^{13}$ looked specifically at the atopic population, largely defined by aeroallergen sensitization, ${ }^{14-18}$ and the majority ${ }^{15-18}$ recruited children with IgE levels of 30-1,300 IU/mL. Omalizumab was administered subcutaneously every 2-4 weeks and dose was calculated based on manufacturer instructions (body weight and serum IgE dependent). ${ }^{13-19}$

Pediatric data. Brodlie et al. conducted a 16-week uncontrolled therapeutic trial of omalizumab in 34 consecutive children (aged 5-16 years) with oral corticosteroid (OCS)dependent asthma and noted that omalizuab use decreased median daily prednisolone requirements (median daily dose reduced from 20 to $5 \mathrm{mg}, P<0.0001$ ), improved quality of life $(P<0.0001)$, and asthma control $(P=0.0001){ }^{13}$

An observational study of 104 children with poorly controlled asthma (aged 6-18 years) by Deschildre et al. noted that omalizumab as add-on therapy significantly reduced exacerbation rates (OCS use) by $72 \%(P<0.0001)$, hospitalization rates by $88.5 \%(P<0.001)$, ICS dose by $30 \%$
$(P<0.001)$, and improved asthma control $(P<0.0001)$ over a year of therapy. ${ }^{14}$

An RDBPCT by Busse et al. of omalizumab versus placebo in addition to standard therapy in 419 children and young adults (age 6-20 years) with persistent uncontrolled asthma in the Inner-City Anti-IgE Therapy for Asthma (ICATA) study found omalizumab in addition to guidelinebased therapy reduced symptoms by $24.5 \%(P<0.001)$, exacerbations (need for OCS) $(48.8 \%$ versus $30.3 \% ; P<0.001)$, and hospitalizations $(6.3 \%$ versus $1.5 \% ; P=0.02)$ despite significantly lower doses of ICS (\% step levels 4-6; $P<0.001)$ and long-acting beta-agonists (LABA) (\% prescribed; $P=0.003$ ) therapy for a 60 -week duration. ${ }^{15}$ A post $h o c$ analysis noted the effect of omalizumab on decreasing seasonal asthma exacerbations in the spring and fall compared with placebo $(P<0.001)$.

Lanier et al. performed an RDBPCT of 627 children aged 6 to $<12$ years old with poorly controlled asthma and noted that omalizumab use for a 1-year period significantly reduced significant asthma exacerbations (worsening symptoms requiring doubling of baseline ICS dose and/or systemic steroids) by $31 \%$ versus placebo $(P=0.007)$, and overall exacerbations by $43 \%(P<0.001)$ versus placebo. ${ }^{16}$

An RDBPCT by Milgrom et al. of 334 children aged 612 years with moderate-to-severe asthma noted that omalizumab use resulted in a significant reduction in ICS dose (median reduction $100 \%$ versus $66.7 \%$; $P=0.001$ ), increased frequency of complete ICS therapy removal $(55 \%$ versus $39 \% ; P=0.004)$, and decreased asthma exacerbations requiring doubling of ICS or OCS use (18.2\% versus $38.5 \%$; $P<0.001)$, although there was little change in asthma symptom scores versus placebo. ${ }^{17}$

The PROSE (Preventative Omalizumab or Step-up Therapy for Fall Exacerbations) study by Teach et al. noted that in 478 children (aged 6-17 years) with $\geq 1$ asthma exacerbations in the year before enrollment, omalizumab use initiated 4-6 weeks before return to school lowered the fall exacerbation rate (OCS use or hospitalization) compared with placebo (odds ratio [OR] 0.48; 95\% CI: 0.25-0.92) but not compared with an ICS boost (OR 0.73; 95\% CI: $0.33-$ 1.64). ${ }^{18}$ In subgroup analysis of children who experienced an exacerbation during the run-in phase, omalizumab was significantly more effective than either placebo (OR 0.12 ; 95\% CI: $0.02-0.64$ ) or ICS boost (OR 0.05; 95\% CI: $0.003-$ 0.98 ) in preventing exacerbations versus placebo.

A 1-year real-life multicenter study of pediatric allergy and pulmonology tertiary centers in Italy noted a significant reduction in asthma exacerbations with omalizumab $(P<0.001)$ compared with the previous year, and a $96 \%$ reduction in hospitalizations. ${ }^{19}$

Adolescent and adult experience. These results are consistent with studies including both adolescents (12 years and older) and adults, which have demonstrated omalizumab efficacy in improving asthma outcomes, including symptom scores, ${ }^{20,21}$ quality of life, ${ }^{22-24}$ asthma exacerbations, ${ }^{21-26}$ emergency department (ED) visits and asthma-related hospitalizations, ${ }^{21,23,25,27}$ ICS and rescue inhaler requirements, ${ }^{28}$ and sputum eosinophil levels compared with placebo. ${ }^{24}$

A recent Cochrane review of omalizumab use in adults and children with asthma found that omalizumab use compared with placebo reduced asthma exacerbations (OR 0.55 ; 95\% CI: 0.42-0.60), reduced hospitalizations (OR 0.16; 
Table 1. Mechanism of Action, Mode of Administration, and Positive Effects of Biologic and Nonbiologic Small Molecular Weight Therapies in Asthma

\begin{tabular}{|c|c|c|c|}
\hline Medication & Mechanism of action & $\begin{array}{c}\text { Mode of } \\
\text { administration }\end{array}$ & Effects identified \\
\hline Omalizumab $^{13-19}$ & $\begin{array}{l}\text { Binds circulating IgE_- } \downarrow \text { IgE levels, } \\
\text { downregulation of IgE receptors on } \\
\text { mast cells, basophils, and dendritic } \\
\text { cells. }\end{array}$ & $\begin{array}{l}\text { SC every } 2-4 \text { weeks } \\
\text { based on body } \\
\text { weight and serum } \\
\text { IgE level }\end{array}$ & $\begin{array}{l}\uparrow \text { asthma control, } \downarrow \text { exacerbations, } \\
\downarrow \text { seasonal exacerbations, } \\
\downarrow \text { hospitalizations, } \\
\downarrow \text { prednisolone, } \uparrow \text { QoL, } \\
\downarrow \text { symptoms }\end{array}$ \\
\hline Ligelizumab $^{46}$ & $\begin{array}{l}\text { Binds circulating IgE_- } \downarrow \text { IgE levels, } \\
\text { downregulation of IgE receptors on } \\
\text { mast cells, basophils, dendritic cells. }\end{array}$ & SC every 2 weeks & $\begin{array}{l}\uparrow \text { provocative concentration of } \\
\text { allergen causing a } 15 \% \\
\text { decrease in } \mathrm{FEV}_{1}\left(\mathrm{PC}_{15}\right) \\
\text { compared with omalizumab }\end{array}$ \\
\hline Mepolizumab $^{48-50}$ & $\begin{array}{l}\text { Binds IL5, which recruits eosinophils } \\
\text { from the bone marrow and promotes } \\
\text { activation and longevity of eosinophils }\end{array}$ & SC every 4 weeks & $\begin{array}{l}\downarrow \text { exacerbations, } \downarrow \text { OCS }, \\
\quad \downarrow \text { symptoms }\end{array}$ \\
\hline Reslizumab $^{62-64}$ & $\begin{array}{l}\text { Binds IL5, which recruits eosinophils } \\
\text { from the bone marrow and promotes } \\
\text { activation and longevity of eosinophils }\end{array}$ & IV every 4 weeks & $\begin{array}{l}\uparrow \text { asthma control, } \\
\quad \downarrow \text { exacerbations, } \downarrow \text { eosinophil } \\
\text { count, } \uparrow \mathrm{FEV}_{1}, \uparrow \mathrm{QoL}\end{array}$ \\
\hline Benralizumab $^{68-71}$ & $\begin{array}{l}\text { Binds IL5 receptor, preventing binding of } \\
\text { IL5 }\end{array}$ & $\begin{array}{l}\text { SC every } 4 \text { or } \\
8 \text { weeks }\end{array}$ & $\begin{array}{l}\downarrow \text { exacerbations, N/S FEV } \\
\\
\downarrow \downarrow \text { OCS }, \downarrow \text { symptoms }\end{array}$ \\
\hline Dupilumab $^{75}$ & Blocks activity of IL4 and IL13 & SC once a week & $\downarrow$ exacerbations, $\uparrow \mathrm{FEV}_{1}$ \\
\hline Lebrikizumab $^{80-82}$ & Binds IL13, thereby blocking its activity & SC every 4 weeks & $\begin{array}{l}\text { N/S asthma control, } \\
\quad \downarrow \text { exacerbations, } \uparrow \mathrm{FEV}_{1}\end{array}$ \\
\hline Tralokinumab $^{85,86}$ & Binds IL13, thereby blocking its activity & SC every $2-4$ weeks & $\mathrm{N} / \mathrm{S}$ exacerbations, $\uparrow \mathrm{FEV}_{1}$ \\
\hline Tezepelumab $^{89,90}$ & $\begin{array}{l}\text { Prevents binding of TSLP with its receptor, } \\
\text { preventing TSLP-initiated inflammatory } \\
\text { response through activation of dendritic } \\
\text { cells and mast cells }\end{array}$ & IV every $2-4$ weeks & $\begin{array}{l}\text { Attenuation of asthmatic } \\
\text { responses, } \downarrow \text { exacerbations, } \\
\uparrow \mathrm{FEV}_{1}\end{array}$ \\
\hline Fevipiprant ${ }^{87,88}$ & $\begin{array}{l}\text { Antagonist to CRTh2, which is a PGD2 } \\
\text { receptor that mediates inflammatory } \\
\text { effects through production of mast cells } \\
\text { and other allergic cells }\end{array}$ & Orally once a day & $\begin{array}{l}\mathrm{N} / \mathrm{S} \text { difference in } \mathrm{FEV}_{1} \text { or } \\
\text { asthma control (except in } \\
\text { subgroup analysis) }\end{array}$ \\
\hline
\end{tabular}

CRTh2, chemoattractant receptor-homologous molecule expressed on T helper 2 cells; $\mathrm{FEV}_{1}$, forced expiratory volume in 1 second; IgE, immunoglobulin-E; IL, interleukin; IV, intravenous; N/S, nonsignificant; OCS, oral corticosteroid; PGD2, prostaglandin D2 receptor; SC, subcutaneous; QoL, quality of life; TSLP, thymic stromal lymphopoietin.

95\% CI: 0.06-0.42), and increased the likelihood of withdrawing ICS therapy (OR 2.50; $95 \%$ CI: 2.00-3.13). ${ }^{29}$

Tertiary prevention has been examined in several of the pediatric studies although effects have been modest. Both Deschildre and Brodlie's studies noted nonsignificant improvements in forced expiratory volume in 1 second $\left(\mathrm{FEV}_{1}\right)$ with omalizumab use $(4.9 \%$ improvement; $P=0.02$, and $0.15 \mathrm{~L}$ improvement; $P=0.1$, respectively) ${ }^{13,14}$ and Milgrom's study noted no significant improvement in $\mathrm{FEV}_{1}$ in the omalizumab group. ${ }^{17}$ The adolescent/adult studies have equally been mixed with predominantly nonsignificant improvements noted in $\mathrm{FEV}_{1}{ }^{24}$

Omalizumab is Food and Drug Administration (FDA) approved for moderate-to-severe asthma in patients aged 6 years and older with environmental allergies (positive skin testing or serum-specific IgE to perennial aeroallergen).

Predictive biomarkers. Several of the pediatric studies have examined predictive markers of omalizumab response although results have been conflicting. Busse et al. found that children with allergy/exposure demonstrated the greatest benefit from omalizumab $(71.2 \%$ reduction in exacerbations). ${ }^{15}$ In contrast, Deschildre et al.'s study did not find any effect modifier on omalizumab response with allergic comorbidities nor any relationship between $\operatorname{IgE}$ level and outcomes. ${ }^{14}$ In their study, age $>12$ years was the only significant factor associated with good response $(53.5 \%$ versus $76 \% ; P=0.02)$, whereas Brodlie et al.'s subgroup analysis showed no improvement based on age. ${ }^{13}$ Teach et al.'s study noted recent asthma exacerbation to be most predictive of omalizumab response. ${ }^{18}$ A post hoc analysis of the ICATA study found significantly greater response to omalizumab in exacerbation reduction with increased asthma severity, as defined by a lower prebronchodilator $\mathrm{FEV}_{1}$ ( $<90 \%$ predicted) or hospitalization in the past 6 months, ${ }^{30}$ whereas another post hoc analysis noted a significantly greater response among children with elevated baseline eosinophil counts of $\geq 300 / \mu \mathrm{L}$. ${ }^{31}$ Exacerbation rates were reduced with omalizumab in the $<300 / \mu \mathrm{L}$ eosinophil group by $5 \%$ (95\% CI: $-48 \%$ to $41 \%, P=0.83$ ), whereas in the $\geq 300 / \mu \mathrm{L}$ group exacerbations were reduced by $39 \%(95 \% \mathrm{CI}: 15 \%-56 \%, P=0.004)$ compared with placebo in adolescents and adults. ${ }^{22}$

The Composite Asthma Severity Index (CASI) has been developed to determine asthma severity by examining daytime and night-time symptoms, albuterol use, lung function, controller medications, and exacerbations. ${ }^{32,33}$ The CASI scores focus on 5 domains, providing a composite score that can be used to indicate the change in burden of asthma with an intervention. ${ }^{32}$ Recently in a post hoc analysis, it has been 


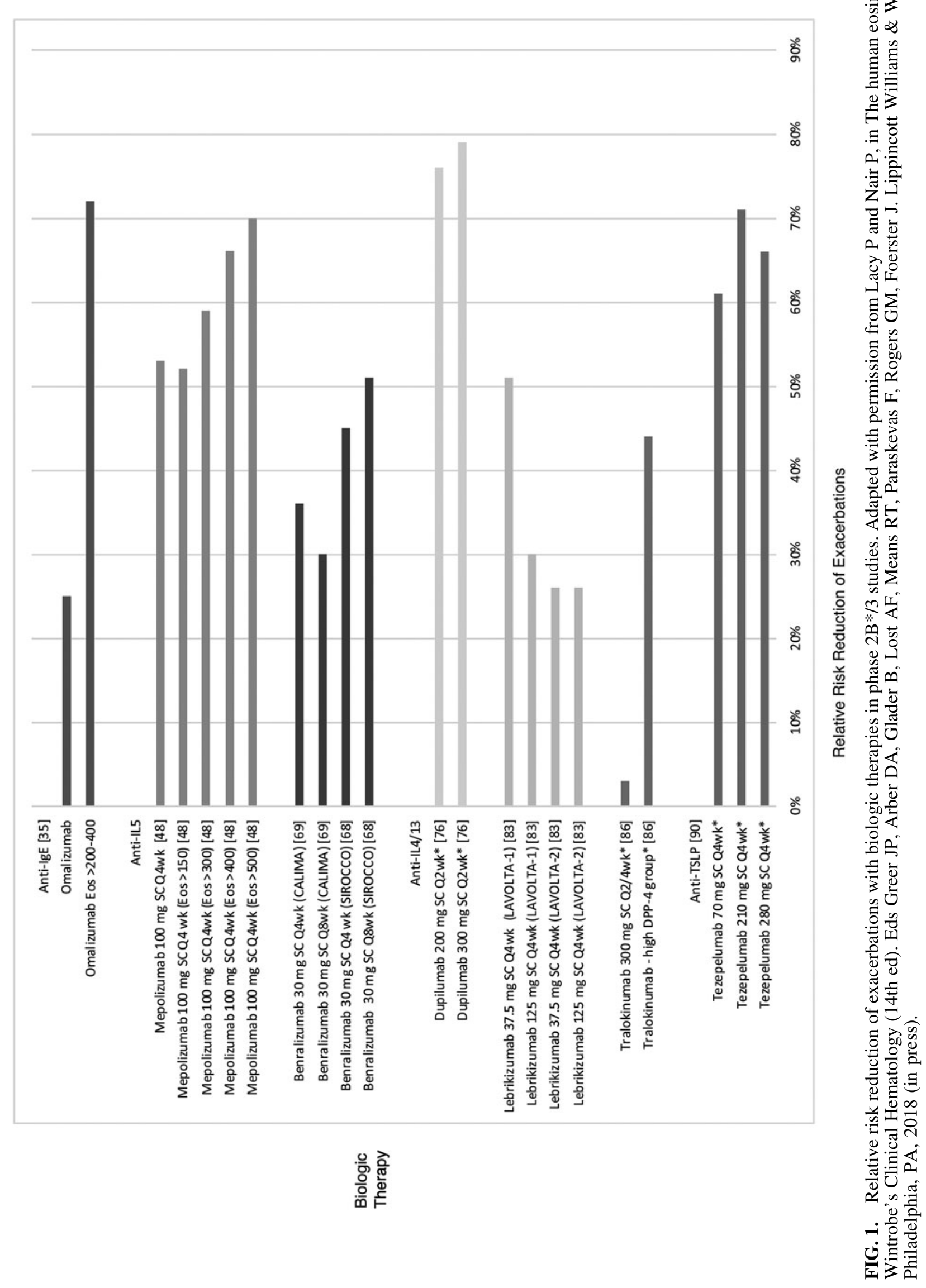




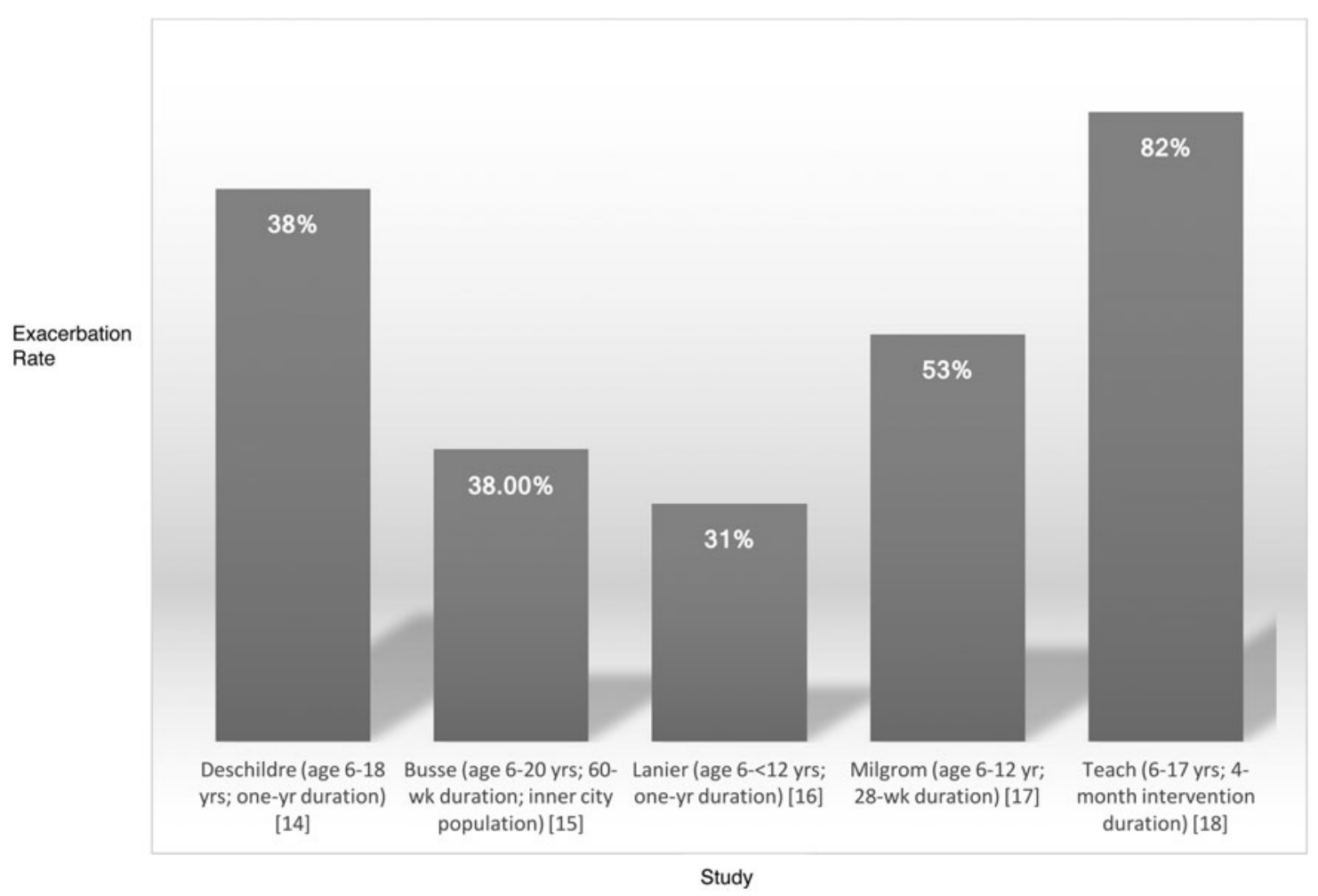

FIG. 2. Decrease in exacerbation rate $(\%)$ with omalizumab compared with placebo. Calculated as [placebo exacerbation rate - omalizumab exacerbation rate]/placebo exacerbation rate $\times 100$.

identified as a useful tool for identifying children most likely to achieve a favorable response to omalizumab. ${ }^{34}$

In the adolescent/adult studies, high levels of type 2 inflammatory markers ${ }^{10}$ such as FeNO levels, ${ }^{22,26}$ eosinophilia, ${ }^{15,22,26}$ periostin levels, ${ }^{22}$ and IgE levels ${ }^{23}$ have predicted improved response to omalizumab, although once again studies are mixed with not all studies consistently identifying these markers as predictive. ${ }^{25}$ A recent study on pooled data from 2 RDBPCTs of omalizumab response noted clinical markers of asthma severity (history of emergency asthma treatment, hospitalization, FEV $1<65 \%$ predicted, requirement for LABA use, or beclomethasone $>600 \mu \mathrm{g} /$ day) and higher baseline blood eosinophil levels $(\geq 300 / \mu \mathrm{L})$ to be predictive of omalizumab response. ${ }^{35}$ In addition, in contrast to the theory that $\mathrm{Th} 2$ markers are predictive, a recent small study noted baseline levels of CXCL12 (chemokine C-X-C motif ligand 12) and IL10 to be predictive of omalizumab response. ${ }^{36}$

Monitoring biomarkers. In Milgrom et al.'s study, there was a reduction in free serum $\operatorname{IgE}$ in the omalizumab group by $95 \%-99 \%$, with greatest reductions observed during the first few days after dosing. ${ }^{17}$ No reduction was noted in the placebo group. Ideally, a reduction in free serum IgE would be a useful monitoring biomarker but this assay is not readily available in clinical laboratories. In the adolescent/ adult studies, omalizumab has been shown to significantly reduce FeNO, alveolar nitric oxide levels, and sputum eosinophil levels as well. ${ }^{24}$ To date, these have not been correlated with the level of clinical response or to differentiate responders from nonresponders.

Advantages and limitations. Omalizumab is one of the few biologic therapies with data in the pediatric population, and studies in this population consistently show a benefit in particular in atopic children, although the extent of a disease- modifying effect is unclear. There are concerns about potential side effects of omalizumab, such as malignancy and anaphylaxis risk. Although 2003 analysis of pooled clinical trial data reported a malignancy risk of $0.5 \%$ in omalizumab-treated patients (compared with $0.2 \%$ of control subjects), ${ }^{37}$ the Epidemiologic Study of Xolair, a prospective cohort of 7,857 adolescents and adults, noted no increased malignancy risk with omalizumab compared with control (hazard ratio [HR] 1.09, 95\% CI: $0.87-1.38) .{ }^{38}$ There is also an $\sim 0.2 \%$ risk of anaphylaxis with omalizumab. ${ }^{39}$

Efficacy in other disorders. Omalizumab has been approved in adults for use in chronic spontaneous urticaria, and this potential benefit is also being studied in children, ${ }^{40}$ and is being studied in severe atopic dermatitis in adults and children, ${ }^{40,41}$ as an addition to oral immunotherapy in children and adults ${ }^{42}$ as well as in the treatment of allergic rhinitis and chronic rhinosinusitis in adults. ${ }^{43}$ In addition, omalizumab has been shown to prevent anaphylaxis in an adolescent with systemic mastocytosis ${ }^{44}$ and to be effective in the management of cutaneous mastocytosis in the pediatric population. ${ }^{45}$

Future needs. Studies are ongoing in omalizumab, including the Preventing Asthma in High Risk Kids study, which is an RDBPCT to determine whether 2 years of omalizumab in children aged 2-3 years will prevent progression to persistent asthma (NCT02570984). With regard to the concerns about anaphylaxis and development of cancer, the experience to date has been reassuring, but with each level of younger age introduction, these factors will have to be monitored. Because there have been reports of anaphylaxis and at unexpected times in relation to duration of treatment and time after dose, it is likely that office administration will continue to be required. In addition, the 
optimal duration of omalizumab treatment and whether it produces a long-lasting effect remain to be determined.

Ligelizumab. In a phase 2 double-blind parallel-group trial in 37 adults with mild allergic asthma, ligelizumab elicited a 3 -fold greater provocative concentration of allergen, causing a $15 \%$ decrease in $\mathrm{FEV}_{1}\left(\mathrm{PC}_{15}\right)$ compared with omalizumab $(P=0.10)$ and 16-fold greater than placebo $(P=0.0001)$ at 12 weeks. ${ }^{46}$ However, wide variability in response was noted from a $<2$ - to $>500$-fold change in bronchial allergen challenge responses. Ligelizumab was administered subcutaneously at doses of 24,72 , or $240 \mathrm{mg}$ every 2 weeks. So far, no studies have been done in children or adolescents, and there is no data on phenotypic response. It does not appear that further studies are planned with ligelizumab. Total IgE increased in this study for both ligelizumab and omalizumab. Basophil surface IgE was reduced in the higher doses of ligelizumab by up to $99 \%$. Ligelizumab is currently in clinical trials for chronic spontaneous urticaria in adults. ${ }^{47}$

\section{Anti-IL-5 medications}

IL5 is a cytokine that recruits eosinophils from the bone marrow and promotes both the activation and longevity of these cells. ${ }^{11}$ There are 3 anti-IL-5 biologic therapies that have been trialed in adolescent and adult asthmamepolizumab, reslizumab, and benralizumab (Fig. 1). None of these biologic therapies have been trialed in children under the age of 12 years. Mepolizumab and reslizumab are humanized monoclonal antibodies against IL5, whereas benralizumab is a humanized monoclonal antibody against the IL5 receptor. The studies performed with the anti-IL5 medications have been largely limited to eosinophilic asthma under the assumption that eosinophilia is predictive of response to these medications, although the criterion for inclusion for level of eosinophilia has varied slightly between studies. Although some data are available in adults, less information is available with adolescents and studies are in progress in children $<12$ years of age.

\section{Mepolizumab}

Adolescent and adult experience. The Mepolizumab as Adjunctive Therapy in Patients with Severe Asthma (MENSA) study randomized 576 adolescents and adults (aged 12-82 years) with severe eosinophilic asthma (serum eosinophils $\geq 150$ cells $/ \mu \mathrm{L}$ at study entry or $\geq 300$ cells $/ \mu \mathrm{L}$ at some time in the previous year) and frequent exacerbations to mepolizumab at a dose of $100 \mathrm{mg}$ subcutaneous (SC) or $75 \mathrm{mg}$ intravenous (IV) every 4 weeks or placebo. ${ }^{48}$ Asthma exacerbations requiring OCS were reduced $47 \%$ and $53 \%(P<0.001))$ with IV and SC mepolizumab compared with placebo, respectively; asthma exacerbations requiring an ED visit were reduced $32 \%$ and $61 \%$ with IV and SC mepolizumab $(P=0.30$ and $P=0.02$ compared with placebo, respectively); asthma exacerbations resulting in hospitalization were reduced $39 \%$ and $69 \%$ with IV and SC mepolizumab $(P=0.33$ and $P=0.03$ compared with placebo, respectively); and asthma symptoms were significantly improved $(P<0.001)$ with both IV and SC mepolizumab compared with placebo. No data specific to the adolescent population included in this study are accessible from the published studies.

The Steroid Reduction with Mepolizumab (SIRIUS) randomized 135 adolescents and adults with severe eosinophilic asthma (6-month history of OCS requirement; blood eosinophil levels of either $\geq 150$ cells $/ \mu \mathrm{L}$ during the optimization phase or $\geq 300$ cells $/ \mu \mathrm{L}$ during the 12 -month period before screening) to mepolizumab (100 mg SC every 4 weeks) or placebo in addition to their maintenance asthma medication and a tapering regimen of OCS. ${ }^{49}$ Mepolizumab significantly increased the likelihood of oral steroid reduction with an overall OR of 2.39 (95\% CI: $1.25-4.56 ; P=0.008)$. Despite this reduction in OCS dose, there was also a significant reduction in asthma symptoms (between-group difference, -0.52 points; $95 \% \mathrm{CI}:-0.87$ to $-0.17 ; P=0.004)$ and asthma exacerbations (doubling of OCS dose, hospital admission, or ED visit) (rate ratio [RR] $0.68,95 \%$ CI: $0.47-0.99 ; P=0.04$ ) in the mepolizumab group. Although adolescents and adults were recruited, the study patients were largely adult in age (age range 16-74 years).

The Dose Ranging, Efficacy, and Safety with Mepolizumab (DREAM) study randomized 621 asthmatics of age 12-74 years with recurrent severe exacerbations and evidence of eosinophilic inflammation (based on sputum eosinophil counts $\geq 3 \%$, FeNO level $\geq 50$ parts $\mathrm{ppb}$, blood eosinophil level of $\geq 0.3 \times 10^{9} / \mathrm{L}$, or deterioration of asthma control with $\leq 25 \%$ reduction in ICS or OCS) to 3 different doses of mepolizumab $(75,250,750 \mathrm{mg}$ IV every 4 weeks) or placebo and noted a significant $39 \%-52 \%$ reduction in asthma exacerbations (OCS use) $(P<0.0001)$, as well as severe exacerbations requiring ED or hospital admissions with meplizumab. ${ }^{50}$ However, no significant improvement in asthma symptom scores or quality of life was noted. Although adolescents and adults were recruited, only adults were randomized in the trial.

Mepolizumab is FDA approved as add-on maintenance therapy in patients who are 12 years and older with eosinophilic asthma.

Predictive biomarkers. The 3 randomized controlled trials above all included only patients with eosinophilic asthma on the basis that an antibody that reduces eosinophil levels would be most effective in eosinophilic asthma. This is supported by studies showing no clinical benefit or improvement in $\mathrm{FEV}_{1}$ with mepolizumab in moderate persistent asthmatics in the absence of eosinophilia. ${ }^{11,51,52}$ The DREAM study noted that reductions in the rate of clinically significant exacerbations with mepolizumab varied based on baseline blood eosinophil count and number of exacerbations in the year before study commencement. MENSA also noted in exploratory multivariate modeling that the only covariate identified that influenced efficacy of mepolizumab on exacerbations was blood eosinophil count at screening, with enhanced response to mepolizumab noted in patients with a blood eosinophil count of $\geq 500$ cells $/ \mu \mathrm{L}$.

Monitoring biomarkers. Mepolizumab has been shown to decrease serum eosinophil counts ${ }^{46,50,51}$ and sputum eosinophil counts ${ }^{50,51}$ compared with placebo. It would be useful to identify other biomarkers that could differentiate the pharmacologic response from the clinical response and serve as indicators of beneficial effect.

Advantages and limitations. To date, there are no studies on children $<12$ years old, and although many studies included adolescents, the study populations were predominantly adult (median age 51 years, minimum age 12 years in pooled trials). ${ }^{53,54}$ In addition, the studies are limited to predominantly eosinophilic asthma. Studies are conflicting regarding a disease-modifying effect. DREAM noted no improvements in $\mathrm{FEV}_{1}$, SIRIUS noted a nonsignificant trend toward greater changes from baseline in the $\mathrm{FEV}_{1}$ before and after 
bronchodilation, whereas MENSA noted a significant improvement in baseline and postbronchodilator $\mathrm{FEV}_{1}$ with both IV and SC mepolizumab compared with placebo ( $P=0.03$ and $P=0.003 / 0.004$, respectively). In addition, side effects such as herpes zoster infection have been noted in clinical trials. ${ }^{55}$

Efficacy in other disorders. Mepolizumab has demonstrated efficacy in the treatment of pediatric eosinophilic granulomatosis with polyangiitis, ${ }^{56}$ and in adults it has shown efficacy for eosinophilic chronic obstructive pulmonary disease, ${ }^{57}$ aspirin-exacerbated respiratory disease ${ }^{58}$ and chronic rhinosinusitis with nasal polyposis. ${ }^{59}$ Mepolizumab and benralizumab are being actively investigated for the treatment of hypereosinophilia ${ }^{60}$ and eosinophilic esophagitis. ${ }^{61}$

Future needs. Data on children $<12$ years are required. Studies are ongoing in this population, including an RDBPCT of children aged 6-17 years of age examining exacerbation rates with mepolizumab compared with placebo in addition to standard asthma care in children who live in an urban area (NCT03292588).

\section{Reslizumab}

Adolescent and adult experience. Two RDBPCTs have been conducted on reslizumab in adolescents and adults with eosinophilic asthma. A phase 3 trial of 374 adolescents and adults (aged 12-75 years) with inadequately controlled eosinophilic asthma (blood eosinophil count $\geq 400$ cells $/ \mu \mathrm{L}$ ) on medium-dose ICS by Bjermer et al. randomized patients to placebo, infusions of $0.3 \mathrm{mg} / \mathrm{kg}$ reslizumab, or $3.0 \mathrm{mg} / \mathrm{kg}$ every 4 weeks for 16 weeks. ${ }^{62}$ This study noted improved asthma control (change in ASUI 0.051; 95\% CI: $0.012-$ $0.089 ; \quad P=0.0094$ and $0.047 ; 95 \%$ CI: $0.009-0.085$; $P=0.016$ for $0.3 \mathrm{mg} / \mathrm{kg}$ and $3 \mathrm{mg} / \mathrm{kg}$ reslizumab, respectively) compared with placebo. However, the quality of life measure trended to improve in the $0.3 \mathrm{mg} / \mathrm{kg}$ dose of reslizumab but was only significant for the higher dose (AQLQ score change $0.28 ; 95 \% \mathrm{CI}:-0.036$ to $0.59 ; P=0.08$ and $0.36 ; 965 \% \mathrm{CI}: 0.05$ to $0.67 ; P=0.02$ for 0.3 and $3 \mathrm{mg} /$ $\mathrm{kg}$ reslizumab, respectively). Only $5 \%$ of study participants were in the adolescent age range but specific results are not reported for this age group.

Two duplicate RDBPCTs (phase 3) in adolescents and adults (age 12-75 years) with uncontrolled eosinophilic asthma (serum eosinophils $\geq 400$ cells $/ \mu \mathrm{L}$ ) on medium-tohigh dose ICS therapy noted significant reduction in asthma exacerbation frequency (study 1: RR 0.50 ; 95\% CI: $0.37-$ 0.67 ; study 2 : 0.41 ; $95 \%$ CI: $0.28-0.59$; both $P<0.0001$ ) with reslizumab $(3.0 \mathrm{mg} / \mathrm{kg}$ IV every 4 weeks $)$, as well as improvements in time to exacerbation (OCS use, doubling of ICS, or asthma-related emergency treatment), asthma control, and quality of life. ${ }^{63}$

A meta-analysis of reslizumab compared with placebo in the treatment of eosinophilic asthma in adolescents and adults noted reslizumab to decrease asthma exacerbations (OR 0.46; 95\% CI: $0.35-0.59 ; P<0.00001)$, blood eosinophil counts (standardized mean difference $[\mathrm{SMD}]=-475.62 ; 95 \% \mathrm{CI}$ : -528.41 to $-422.93 ; P<0.00001)$, improve asthma control (SMD $=-0.26 ; 95 \%$ CI: -0.36 to $-0.16 ; P<0.00001)$, and improve $\mathrm{FEV}_{1}$ (standardized mean difference $=0.16 ; 95 \% \mathrm{CI}$ : $0.10-0.23 ; P<0.00001)$ compared with placebo, supporting a disease-modifying effect as well. ${ }^{64}$

Reslizumab is FDA approved for add-on therapy in adults aged 18 and older with eosinophilic asthma.
Predictive biomarkers. As with mepolizumab, the presence of eosinophilia as a biomarker for reslizumab efficacy was demonstrated in an RDBPCT of reslizumab in adult asthmatics, which demonstrated no clinically significant effect on either lung function or symptom control in patients unselected for baseline eosinophil levels. ${ }^{65}$ However, in Bjermer et al.'s ${ }^{62}$ study, baseline blood eosinophil levels did not influence magnitude of improvement in $\mathrm{FEV}_{1}$, although the number of patients in the sensitivity analyses was small.

Monitoring biomarkers. Reslizumab has been shown to decrease blood eosinophil counts compared with placebo in several randomized controlled trials, but it has not been correlated with the beneficial effect or responder/nonresponder populations. ${ }^{62,64,65}$

Advantages and limitations. Studies are limited to eosinophilic asthma, and no studies have been done to date on children under the age of 12 years old. In addition, side effects, such as elevation in creatine phosphokinase levels, have been noted in clinical trials. ${ }^{66}$

Efficacy in other disorders. Reslizumab is being studied for use in eosinophilic esophagitis in children. ${ }^{67}$

Future needs. Studies are ongoing on the use of reslizumab in the adolescent population such as an RDBPCT of reslizumab compared with placebo in adolescents and adults with uncontrolled eosinophilic asthma, examining the efficacy of reducing asthma exacerbations (NCT 02452190). Studies in the pediatric population are required.

\section{Benralizumab}

Adolescent and adult experience. Two RDBPCTs (phase 3) of adolescents and adults aged 12-75 years with severe uncontrolled asthma on high-dose ICS and LABA therapy (SIROCCO and CALIMA) enrolling patients at 677 research centers internationally with similar study designs have noted benralizumab to significantly improve exacerbation rates and asthma symptoms compared with placebo in patients with blood eosinophil counts of $\geq 300$ cells $/ \mu \mathrm{L}$ (who were stratified for inclusion in primary analysis). ${ }^{68,69}$ In the SIROCCO study, patients with lower blood eosinophil counts had reduced exacerbation rates (use of OCS, ED visit, and inpatient hospital stay due to asthma) with benralizumab (30 mg SC every 4 or 8 weeks) $(P=0.047)$ and improvement in asthma symptoms $(P=0.4)$, but other endpoints were not significant and the treatment effect was "smaller." 68 Although the SIROCCO and CALIMA studies recruited adolescents and adults, the majority of patients randomized were adults. Some studies have noted an improvement in $\mathrm{FEV}_{1}$ with benralizumab, ${ }^{68,69}$ although in others no improvement in $\mathrm{FEV}_{1}$ was noted. $^{70}$

An RDBPCT of 369 adults with severe asthma requiring OCS use noted that benralizumab use $(30 \mathrm{mg}$ SC either every 4 weeks or every 8 weeks) reduced median final oral glucocorticoid dose from baseline by $75 \%$, compared with a $25 \%$ reduction in the placebo group $(P<0.001)$. Benralizumab use reduced the annual exacerbation rate (increase in OCS, ED visit, and hospitalization) by $55 \%$ versus placebo when administered every 4 weeks $(P=0.003)$ and by $70 \%$ when administered every 8 weeks $(P<0.001)$. No significant effect on $\mathrm{FEV}_{1}$ was noted. $^{71}$

Benralizumab is FDA approved for patients with severe asthma aged $\geq 12$ years, who have an eosinophilic phenotype. 
Predictive biomarkers. Increased blood eosinophil levels ( $>300$ cells $/ \mu \mathrm{L})$ have been identified in some studies as a biomarker of benralizumab efficacy. ${ }^{68,69,72}$ However, a pooled analysis of SIROCCO and CALIMA study data supported the use of benralizumab in patients with blood eosinophil counts $\geq 150$ cells $/ \mu \mathrm{L}^{73}$ and a newly released subsequent pooled analyses extended the efficacy irrespective of eosinophil count, although noting that the higher the eosinophil count the greater the benefit. ${ }^{74}$

Monitoring biomarkers. Benralizumab has been shown to decrease blood eosinophil counts, but studies are not available to show differentiation between responders and nonresponders in the magnitude of reduction in blood eosinophils. ${ }^{69,70}$

Advantages and limitations. There are a small number of studies thus far that are limited to the adult and adolescent population. Studies in children, and further studies in the adolescent population, are required.

Efficacy in other disorders. None has been studied to date.

Future needs. Studies are ongoing, with the MIRACLE study randomizing adolescents and adults with uncontrolled asthma despite moderate-to-high dose ICS plus LABA therapy to benralizumab versus placebo and measuring exacerbation rates as primary outcome measure. Patients are stratified based on eosinophil count (NCT03186209). The eosinophil level most predictive of response remains to be determined, and no studies have been done yet with benralizumab in asthmatic children $<12$ years of age.

\section{Anti-IL4 and IL13}

The IL4 cytokine is an essential cytokine to T helper 2 (Th2) cell polarization, whereas the IL13 cytokine is associated with periostin production in the bronchial epithelial cells, ultimately resulting in smooth muscle contraction, mucus production, airway remodeling and hyper-responsiveness, and goblet cell hyperplasia. ${ }^{52}$ IL13 also works with IL4 to result in IgE production. The IL4 receptor (alpha subunit) is critical for both IL4 and IL13 signal transduction. There has been one RDBPCT on the use of an anti-IL4 alpha receptor antibody (dupilumab) and the studies on the anti-IL13 biologic tralokinumab are limited to 2 phase 2 studies (Fig. 1). The data are more robust for the anti-IL13 biologic lebrikizumab although results are inconsistent in terms of lebrikizumab's efficacy.

Dupilumab. Dupilumab is a human monoclonal antibody to the alpha subunit of the IL4 receptor, thereby blocking the activity of IL4 and IL13.

Adolescent and adult experience. An RDBPCT of dupilumab use in 104 adults (18-65 years) with moderate-tosevere asthma and high blood or sputum eosinophil counts ( $>300$ cells $/ \mu \mathrm{L} ;>3 \%$, respectively) on medium-to-high dose ICS plus LABAs resulted in an $87 \%$ reduction in asthma exacerbations (reduction of $30 \%$ or more in peak expiratory flow, 6 or more additional reliever inhalations, OCS use, and hospitalization) (44\% versus 6\%; OR 0.08 ; $95 \%$ CI: $0.02-$ $0.28 ; P<0.001)$ and increased time to asthma exacerbation (HR $0.10 ; 95 \%$ CI: $0.03-0.32 ; P<0.001$ ) despite stopping LABA and ICS therapy while on dupilumab (300 mg SC once a week) compared with placebo. ${ }^{75}$ There was noted improvement in $\mathrm{FEV}_{1}$ as early as the second week of treatment, which was maintained for the 12 weeks of the study $(P<0.001)$. An RDBPCT of dupilumab $(300 \mathrm{mg}$ SC every 2 weeks for 24 weeks) in 210 adults with OCSdependent asthma noted a 59\% (95\% CI: 37\%-74\%) decrease in severe exacerbations in the dupilumab group despite a $-70.1 \%$ reduction in OCS $(P<0.001) .{ }^{76}$ An RDBPCT of 1902 adolescents and adults (aged 12 years and older) with uncontrolled asthma noted that dupilumab (200 or $300 \mathrm{mg} \mathrm{SC}$ every 2 weeks) reduced severe exacerbations by $47.7 \%$ compared with pacebo $(P<0.001)$ while increasing $\mathrm{FEV}_{1}$ compared with placebo $(P<0.001) .^{77}$

Dupilumab has been FDA approved for adolescents and adults aged 12 years and older with moderate-to-severe asthma as add-on maintenance therapy.

Predictive biomarkers. There are few data on biomarkers that may predict improved response. A phase $2 \mathrm{~B}$ RDBPCT by Wenzel et al. with 769 adults on medium-to-high dose ICS and LABA therapy randomized to dupilumab (200 or $300 \mathrm{mg}$ SC every 2-4 weeks) versus placebo noted significant efficacy in improving $\mathrm{FEV}_{1}$ as well as decreasing severe exacerbations, irrespective of baseline eosinophil levels, suggesting that this may not be a specific biomarker. ${ }^{78}$ A commentary on this study did note that IL5 is more specific to eosinophilia than IL4, and that other biomarkers such as FeNO or serum periostin levels may be more predictive, but these have not been studied to date. ${ }^{79}$

Monitoring biomarkers. Dupilumab has been shown to reduce FeNO levels ${ }^{75,78}$ and other levels of Th2 inflammation (TARC, eotaxin-3, and IgE). ${ }^{75}$

Advantages and limitations. There are a small number of studies thus far that are limited to the adolescent and adult population. Studies in children, and further studies in the adolescent population, are required.

Efficacy in other disorders. Dupilumab has been extensively studied in the treatment of atopic dermatitis in adults and children ${ }^{80,81}$ and is being investigated as a therapy in adults with eosinophilic esophagitis (NCT 02379052).

Future needs. Further studies are required to determine the reproducibility of this result, as well as to assess its efficacy in children and adolescents. Studies are ongoing with an RDBPCT of dupilumab in children aged 6 to $<12$ years with uncontrolled persistent asthma (NCT02948959).

Lebrikizumab. Lebrikizumab is a humanized monoclonal antibody against IL13.

Adolescent and adult experience. A phase 2 RDBPCT by Corren et al. of lebrikizumab ( $250 \mathrm{mg}$ SC once a month) in 219 adults with asthma uncontrolled on medium-to-high dose ICS therapy noted a significant improvement in $\mathrm{FEV}_{1}$ after 12 weeks of lebrikizumab (5.5\% points higher than placebo; $P=0.02$ ) although no significant change was noted in several other secondary efficacy outcomes including asthma control $(P=0.85)$, with subgroup analysis demonstrating that adults with high periostin levels had significantly improved $\mathrm{FEV}_{1}$ with lebrikizumab $(8.2 \%$ points higher than placebo; $P=0.03)$ compared with the low-periostin subgroup $(1.6 \%$ points higher than placebo; $P=0.61){ }^{82}$

A phase 2 RDBPCT by Noonan et al. of 212 adults aged 18-65 years not receiving ICS therapy noted no significant improvement in $\mathrm{FEV}_{1}$ with multiple different doses of lebrikizumab $(125,250$, or $500 \mathrm{mcg}$ SC monthly) compared with placebo even with stratification based on periostin levels, although there was a reduced risk of treatment failure in all lebrikizumab dose groups compared with placebo (HR, 0.21; 95\% CI: $0.09-0.47 ; P<0.001){ }^{83}$ 
Pooled data from 2 RDBPCTs on multiple doses of lebrikizumab in adults with uncontrolled asthma despite medium-to-high ICS use and a second controller found that lebrikizumab use $(37.5,125$, and $250 \mathrm{mg} \mathrm{SC}$ every 4 weeks) reduced the rate of asthma exacerbations (OCS use or hospitalizations), which was more pronounced in the periostinhigh subgroup (60\% reduction with lebrikizumab compared with periostin-high placebo group; 95\% CI: 18\%-80\%) compared with the periostin-low subgroup (5\% reduction with lebrikizumab compared with periostin-low placebo group; 95\% CI: $-81 \%$ to $47 \%$ ) and an improvement in $\mathrm{FEV}_{1}$ that was once again more pronounced in the periostin-high group $(9.1 \%$ improvement from baseline versus placebo in periostin-high group versus $2.6 \%$ improvement versus placebo in the periostin-low group). ${ }^{84}$

Replicate phase 3, RDBPCTs (LAVOLTA I and LAVOLTA II) of 2 concentrations of lebrikizumab (37.5 or $125 \mathrm{mg}$ SC every 4 weeks) in adults with uncontrolled asthma (1,081 patients in LAVOLTA I and 1,067 in LAVOLTA II) found that lebrizikumab reduced exacerbation rates (OCS use or hospitalization) in high biomarker (periostin/serum eosinophil) adults compared with placebo in both the $37.5 \mathrm{mg}$ group (RR 0.49; 95\% CI: $0.34-0.69 ; P<0.0001)$ and in the $125 \mathrm{mg}$ dose group (RR 0.70; 95\% CI: 0.51-0.95; $P=0.0232) .{ }^{85}$ In LAVOLTA II, exacerbation rates were also reduced in the high biomarker patients compared with placebo in the $37.5 \mathrm{mg}$ dose (RR 0.74; 95\% CI: 0.054-1.01; $P=0.06)$ and in the $125 \mathrm{mg}$ dose (RR 0.74; $95 \%$ CI: 0.54 $1.02 ; P=0.06)$ groups although not significantly.

Predictive biomarkers. Periostin levels have emerged from the mentioned studies as a biomarker strongly correlated with lebrikizumab efficacy. Noonan et al.'s study found no difference in $\mathrm{FEV}_{1}$ improvement based on periostin levels, suggesting as noted in a recent review that interaction of IL13 with ICS might contribute to response ${ }^{52}$ as the Noonan study did demonstrate a similar effect on IL13 activity (with decreases in serum IgE, FeNO levels, and blood eosinophil numbers) with lebrikizumab as other studies, such as Corren et al.'s study. It has been pointed out, however, that as periostin is a product of bone turnover, there may be higher baseline levels of this biomarker in children, which could limit its applicability as a biomarker of efficacy in the pediatric population. ${ }^{52}$

Monitoring biomarkers. Lebrikizumab has been associated with a decrease in FeNO compared with placebo $(P<0.001)$, with greater reductions in FeNO in the high periostin groups. ${ }^{82}$

Advantages and limitations. There are a small number of studies thus far that are limited to the adult population. Studies in children, and further studies in the adolescent population, are required. To date, further evaluation of lebrikizumab in asthma has been stopped due to the failure to meet endpoint in 1 adult study.

Efficacy in other disorders. Lebrikizumab is being studied in the treatment of adults with moderate-to-severe atopic dermatitis. ${ }^{86}$

Future needs. Studies on adolescents and younger children are required.

Tralokinumab. Tralokinumab is a human monoclonal antibody against IL13. A phase 2 RDBPCT of multiple doses of tralokinumab $(150,300$, or $600 \mathrm{mg}$ SC every 2 weeks) versus placebo in 194 adults aged 18-65 years with moderate-tosevere asthma noted no significant improvement in asthma control $(P=0.375), \mathrm{FEV}_{1}(P=0.072)$ with tralokinumab although there was a significant decrease in beta-agonist use $(P=0.02){ }^{87}$

A phase 2 RDBPCT of tralokinumab in 452 adults (aged 18-75 years) with severe uncontrolled asthma noted that tralokinumab use (300 mg SC every 2 or 4 weeks) did not result in significant percentage change in annual asthma exacerbation rates (OCS use) versus placebo ( 2 weeks: $6 \%$; 95\% CI: $-31 \%$ to $33 \% ; P=0.71$ and 4 weeks: $-2 \%$ : $95 \%$ CI: $-46 \%$ to $29 \% ; P=0.90){ }^{88}$ Prebronchodilator $\mathrm{FEV}_{1}$ was significantly increased in the tralokinumab every 2 weeks group compared with placebo (change from baseline $7.3 \%$; 95\% CI: $2.6 \%-12.0 \%: P=0.003)$ but not in the tralokinumab every 4 weeks group $(1.8 \%$; $95 \%$ CI: $-2.9 \%$ to $6.6 \%$; $P=0.45$ ). Subgroup analysis identified adults with a high baseline serum dipeptidyl peptidase- 4 , or high serum periostin levels had improved $\mathrm{FEV}_{1}$, asthma control, and exacerbation rates compared with placebo.

\section{Fevipiprant}

Fevipiprant is a competitive antagonist to chemoattractant receptor-homologous molecule expressed on T helper 2 cells (CRTh2). CRTh2 is a prostaglandin D2 receptor that mediates inflammatory effects largely through its production by allergic cells such as mast cells. Results with fevipiprant have been inconsistent and limited to phase 2 studies. One study of 157 adults with mild-to-moderate allergic asthma who were weaned off ICS and LABA therapy noted no difference between fevipiprant (500 $\mathrm{mg}$ orally once daily) and placebo in FEV $_{1}(P=0.41)$ or asthma control $(P=0.11)$ between the groups ${ }^{87}$ However, a subgroup analysis of adults with more severe airway obstruction $\left(\mathrm{FEV}_{1}<70 \%\right.$ predicted) did demonstrate some significant improvements in both symptoms $(P=0.009)$ and lung function $(P=0.002)$ compared with placebo. Another phase 2 RDBPCT of 61 adults with moderate-to-severe asthma and elevated sputum eosinophil count $(\geq 2 \%)$ noted a reduction in airway eosinophilic inflammation $(P=0.0014)$ in the fevipiprant $(225 \mathrm{mg}$ twice a day orally) group. ${ }^{90}$

At this time, no studies have been complete in children and adolescents, and the biomarker profile of patients most likely to respond to fevipiprant remains unknown. However, several studies are randomizing adolescents and adults with moderateto-severe asthma to fevipiprant versus placebo to determine efficacy (NCT03215758, NCT03226392, NCT02563067, and NCT0255568).

\section{Tezepelumab}

Tezepelumab is a human anti-TSLP monoclonal immunoglobulin that prevents binding of TSLP with its receptor, preventing TSLP-initiated inflammatory responses through activation of dendritic cells and mast cells. There has only been one proof-of-concept RDBPCT of tezepelumab (700 mg IV once a month) in 31 adults with allergic asthma that noted attenuation of both the early and late asthmatic responses, with a $45.9 \%$ smaller decrease in $\mathrm{FEV}_{1}$ during the late phase response after 12 weeks of treatment $(P=0.02)$ as well as significantly decreased blood and sputum eosinophils both before and after allergen challenge (Fig. 1). ${ }^{91}$

A phase 2 RDBPCT of tezepelumab in adults with uncontrolled asthma despite medium-to-high ICS and LABA 
therapy noted significant reductions in exacerbation rates $(P<0.001)$ with tezepelumab $(70 \mathrm{mg}$ every 4 weeks, $210 \mathrm{mg}$ every 4 weeks, or $280 \mathrm{mg}$ every 2 weeks), independent of baseline serum eosinophil levels, as well as an improvement in $\mathrm{FEV}_{1}(P=0.002) .{ }^{92}$ Limitations are similar to fevipiprant, as there is a paucity of studies, no studies have been done in the pediatric population, the biomarker profile of those most likely to respond remains unknown, and it is unclear whether there will be a disease-modifying effect with this medication. No ongoing studies at this time with anti-TSLP biologics are being done in children or adolescents; studies remain limited to adults (NCT02698501).

\section{Conclusion: Current Guidelines and Future Directions}

Several international asthma guidelines now include the use of omalizumab and anti-IL5 medications for patients with severe asthma, including children and adolescents. The National Heart, Lung and Blood Institute's Expert Panel 3 (NHLBI EPR3) guideline recommends the use of omalizumab as adjunctive therapy in patients $\geq 12$ years old who have atopic severe persistent asthma inadequately controlled with high-dose ICS and LABA therapy (ie, step 5 or 6). ${ }^{93}$

The Global Initiative for Asthma (GINA) 2017 update recommends phenotype-guided add-on treatment with omalizumab in patients $\geq 6$ years with severe allergic (elevated IgE) asthma and mepolizumab or reslizumab in patients $\geq 12$ years with eosinophilic asthma as step 4 therapy. ${ }^{94}$

The Canadian Thoracic Society (CTS) recommends omalizumab in patients $\geq 6$ years with severe asthma (inadequately controlled on high dose ICS and at least 1 other controller), sensitization to $\geq 1$ perennial aeroallergen, and serum IgE levels between 30 and 1,300 IU/mL (6-11 years) or $30-700 \mathrm{IU} / \mathrm{mL}$ ( $\geq 12$ years). ${ }^{9}$ The CTS also recommends anti-IL5 therapies in adults with severe eosinophilic corticosteroid-dependent asthma in an attempt to decrease/ withdraw OCSs.

Although there is expanding evidence for biologic therapies in the pediatric population for some medications, such as omalizumab, the evidence remains limited to adults for the majority of this class of medications. Although most of the evidence is supportive of the role of these medications in severe asthma, however, asthma in childhood is quite different from asthma in adulthood, and results from adult studies may not be extrapolated to the pediatric population. For example, there is a higher prevalence of asthma in male children, whereas adult females have more severe and persistent disease. ${ }^{1}$ Adult onset asthma may vary phenotypically from pediatric onset asthma ${ }^{1}$ with pediatric asthma more commonly allergic in nature. ${ }^{95}$

Many other questions remain, such as the utility of currently available biomarkers (with issues such as significant fluctuation of serum eosinophil levels and FeNO) as well as whether the biologics are as effective in all pediatric populations, as disease prevalence and severity are more common in the multiple race, African American, and American Indian children than it is in Caucasian children. ${ }^{1}$ In addition, tolerability of parenteral medications by children and their families remains to be seen, although fevipiprant is an oral medication.

Moving forward, as studies continue to define the role of these biologic medications in the pediatric population, there is the emergence of an individualized approach to the asthmatic child, with the goal of decreasing the burden of asthma severity in childhood and advancing application to disease modification and prevention strategies. Long-term studies will be important to determine whether the medication has an effect on preventing ongoing loss in pulmonary function or improving pulmonary function, perhaps as an indicator of the reversal of airway remodeling. To date, the most experience in children with severe asthma has been with omalizumab, which is now approved to 6 years of age in some countries. Therefore, if the serum $\operatorname{IgE}$ is within limits for the age considered, it is usually considered as the first choice. The clinical impact appears to be on reducing the risk of exacerbations and also the possibility of reducing medication requirements. Next, 2 forms of anti-IL5 are available for use in some countries for adolescents of 12 years of age, specifically mepolizumab and benralizumab. A blood eosinophil count $>300$ cells $/ \mu \mathrm{L}$ and perhaps 150 cells $/ \mu \mathrm{L}$ is associated with an increased likelihood of achieving a favorable response on reducing exacerbations. More information and potential approval of medications, such as dupilumab, is anticipated, wherein experience in adults and adolescents shows effect on reducing exacerbations, improving pulmonary function, and the absence of significant adverse effects, such as anaphylaxis. ${ }^{96}$ Some biologics are being considered for home administration. It will be important to assure efficacy and low risk to allow this be done safely and also important to assess adherence to treatment with home administration.

In addition, the NIAID Inner City Asthma Consortium and the NHLBI Precision Interventions for Severe and/or Exacerbation Prone Asthma (PrecISE) Network are conducting and designing studies to obtain more information on the use of biologics in children as well as adults and developing information on predictive and monitoring biomarkers. This information should be very helpful in personalizing the selection of these medications for children and also for evaluating their potential in altering the course of the disease when it begins in childhood.

Overall, it will be important to define predictive and monitoring biomarkers to assess the likelihood a patient will respond to a biologic and also to determine whether there is a favorable response to continue the biologic. This will provide a profile of those patients most likely to receive a favorable response and also to discontinue a medication if there is low likelihood of a response. Long-term studies will be needed to determine whether the biologic prevents progression of the disease and whether there is a chance for the biologic to further prevent or even reverse airway damage that has already occurred. While new medications are being introduced that have an opportunity to significantly impact the disease, benefit versus risk must be monitored to determine what favorable response patients are most likely to show.

\section{Acknowledgment}

No honorarium, grant, or other form of payment was given to write the article. No funding was received from any source.

\section{Author Disclosure Statement}

E.M.A. has received moderator fees from Novartis. A.B.B. has consulted to and/or received honoraria from 
AstraZeneca, Boegringer Ingelheim, and Novartis, and is a member of the GINA Scientific Committee and co-author of the GINA global strategy for asthma management and prevention. S.J.S. has consulted for Aerocrine, Astra Zeneca, Boehringer-Ingelheim, Daiichi Sankyo, Glaxo Smith Kline, Genentech, Novartis, Roche, and Teva and has received research support from the National Institutes of Health, the National Heart, Lung, and Blood Institute, GlaxoSmithKline, and the Colorado Department of Public Health and Environment Colorado Cancer, Cardiovascular, and Pulmonary Disease Program. He is also a former member of the Global Initiative for Asthma Scientific Committee and the National Asthma Education and Prevention Expert Panel 3.

\section{References}

1. American Academy of Allergy Asthma and Immunology. Asthma Statistics. www.aaaai.org/about-aaaai/newsroom/ asthma-statistics

2. Zahran HS, Bailey CM, Damon SA, et al. Vital signs: asthma in children-United States, 2001-2016. Morb Mortal Wkly Rep 2018; 67:149-155.

3. Government of Canada. Fast facts about asthma: Data compiled from the 2011 Survey on Living with Chronic Diseases in Canada. www.phac-aspc.gc.ca/cd-mc/crd-mrc/ asthma_fs_asthme-eng php

4. Lougheed MD, Lemiere C, Ducharme FM, et al. Canadian thoracic society 2012 guideline update: diagnosis and management of asthma in preschoolers, children and adults. Can Respir J 2012; 19:127-164.

5. Barksy EE, Giancola LM, Baxi SN, et al. A practical approach to severe asthma in children. Ann Am Thorac Soc 2018; 15:399-408.

6. Asthma in the US, Vital Statistics. www.cdc.gov/vitalsigns/ asthma/index.htm

7. Nurmagambetov $T$, Kuwahara R, Garbe P. The economic burden of asthma in the United States, 2008-2013. Ann Am Thorac Soc 2018; 15:348-356.

8. Szefler SJ, Zeiger RS, Haselkorn T, et al. Economic burden of impairment in children with severe or difficult-to-treat asthma. Ann Allergy Asthma Immunol 2011; 107:110-119.

9. FitzGerald JM. Recognition and management of severe asthma: a Canadian Thoracic Society position statement. Can J Respir Crit Care Sleep Med 2017; 1:199-221.

10. Haahtela T, Selroos O. Chapter 1: a population management model of asthma and allergy: Case Finland. Personalizing asthma management for the clinician, 1st ed. St.Louis, Missouri: Elsevier Publishing, 2018, pp. 1-10.

11. Hoch HE, Anderson III WC, Szefler SJ. Kendig and chernick's disorders of the respiratory tract in children, 9th ed. Missouri: Elsevier Publishing, 2019.

12. Arm JP, Bottoli I, Skerjanec A, et al. Pharmacokinetics, pharmacodynamics and safety of QGE031 (ligelizumab), a novel high-affinity anti-IgE antibody, in atopic subjects. Clin Exp Allergy 2014; 44:1371-1385.

13. Brodlie M, McKean MC, Moss S, et al. The oral corticosteroid-sparing effect of omalizumab in children with severe asthma. Arch Dis Child 2012; 97:604-609.

14. Deschildre A, Marguet C, Salleron J, et al. Add-on omalizumab in children with severe allergic asthma: a 1-year real life survey. Eur Respir J 2013; 42:1224-1233.

15. Busse WW, Morgan WJ, Gergen PJ, et al. Randomized trial of omalizumab (anti-IgE) for asthma in inner-city children. N Engl J Med 2011; 364:1005-1015.
16. Lanier B, Bridges T, Kulus M, et al. Omalizumab for the treatment of exacerbations in children with inadequately controlled allergic (IgE-mediated) asthma. J Allergy Clin Immunol 2009; 124:1210-1216.

17. Milgrom H, Berger W, Nayak A, et al. Treatment of childhood asthma with anti-immunoglobulin E antibody (omalizumab). Pediatrics 2001; 108:E36.

18. Teach SJ, Gill MA, Togias A, et al. Preseasonal treatment with either omalizumab or an inhaled corticosteroid boost to prevent fall asthma exacerbations. J Allergy Clin Immunol 2015; 136:1476-1485.

19. Licari A, Castagnoli R, Denicolo C, et al. Omalizumab in children with severe allergic asthma: the Italian real-life experience. Curr Respir Med Rev 2017; 13:36-42.

20. Holgate ST, Churchalin AG, Hebert J, et al. Efficacy and safety of a recombinant anti-immunoglobulin E antibody (omalizumab) in severe allergic asthma. Clin Exp Allergy 2004; 34:632-638.

21. Lafeuille MH, Gravel J, Zhang J, et al. Association between consistent omalizumab treatment and asthma control. J Allergy Clin Immunol 2013; 1:51-57.

22. Hanania NA, Alpan O, Hamilos DL, et al. Omalizumab in severe allergic asthma inadequately controlled with standard therapy: a randomized trial. Ann Intern Med 2011; 154:573-582.

23. Humbert M, Beasley R, Ayres J, et al. Benefits of omalizumab as add-on therapy in patients with severe persistent asthma who are inadequately controlled despite best available therapy (GINA 2002 step 4 treatment): INNOVATE. Allergy 2005; 60:309-316.

24. Tajiri $\mathrm{T}$, Niimi A, Matsumoto $\mathrm{H}$, et al. Comprehensive efficacy of omalizumab for severe refractory asthma: a time-series observational study. Ann Allergy Asthma Immunol 2014; 113:470-475.

25. Bousquet J, Cabrera P, Berkman N, et al. The effect of treatment with omalizumab, an anti-IgE antibody, on asthma exacerbations and emergency medical visits in patients with severe persistent asthma. Allergy 2005; 60:302308.

26. Hanania NA, Wenzel S, Rosen K, et al. Exploring the effects of omalizumab in allergic asthma: an analysis of biomarkers in the EXTRA study. Am J Respir Crit Care Med 2013; 187:804-811.

27. Grimaldi-Bensouda L, Zureik M, Aubier M, et al. Does omalizumab make a difference to the real-life treatment of asthma exacerbations?: results from a large cohort of patients with severe uncontrolled asthma. Chest 2013; 143: 398-405.

28. Holgate ST, Chuchalin AG, Hebert J, et al. Efficacy and safety of a recombinant anti-immunoglobulin E antibody (omalizumab) in severe allergic asthma. Clin Exp Allergy 2004; 34:632-638.

29. Normansell R, Walker S, Milan SJ, et al. Omalizumab for asthma in adults and children. Cochrane Database Syst Rev 2014; CD003559.

30. Busse WW, Haselkorn T, Rosen K, et al. Greater treatment benefit with omalizumab in children with increased asthma severity: exploratory analyses from the inner-city anti-IgE therapy for asthma (ICATA) study. J Allergy Clin Immunol 2018; 141:AB14.

31. Szefler SJ Casale TB, Rosen K, et al. Baseline blood eosinophils and reduction of asthma exacerbations by omalizumab in children with moderate-to-severe allergic asthma. J Allergy Clin Immunol 2017; 139:AB83. 
32. Wildfire JJ, Gergen PJ, Sorkness CA, et al. Development and validation of the Composite Asthma Severity Index- an outcome measure for use in children and adolescents. J Allergy Clin Immunol 2012; 129:694-701.

33. Krouse RZ, Sorkness CA, Wildfire JJ, et al. Minimally important differences and risk levels for the Composite Asthma Severity Index. J Allergy Clin Immunol 2017; 139: 1052-1055.

34. Szefler SJ, Haselkorn T, Ortiz B, et al. The composite asthma severity index: a tool for assessing impact of omalizumab treatment in children with moderate-to-severe persistent allergic asthma. J Allergy Clin Immunol 2018; 141:B100.

35. Casale TB, Chipps BE, Rosen K, et al. Response to omalizumab using patient enrichment criteria from trials of novel biologics in asthma. Allergy 2018; 73:490-497.

36. Suzukawa M, Matsumoto H, Ohshima N, et al. Baseline serum CXCL10 and IL-12 levels may predict severe asthmatics' responsiveness to omalizumab. Respir Med 2018; 134:95-102.

37. Fernandez C. Clinical data do not suggest a causal relationship between omalizumab therapy and cancer. Proc Am Thorac Soc 2005; 2:A359.

38. Long A, Rahmaoui A, Rothman KJ, et al. Incidence of malignancy in patients with moderate-to-severe asthma treated with or without omalizumab. J Allergy Clin Immunol 2014; 134:560-567.

39. Limb SL, Starke PR, Lee CE, et al. Delayed onset and protracted progression of anaphylaxis after omalizumab administration in patients with asthma. J Allergy Clin Immunol 2007; 120:1378-1381.

40. Licari A, Marseglia A, Caimmi S, et al. Omalizumab in children. Paediatr Drugs 2014; 16:491-502.

41. Ring J, Alomar A, Bieber T, et al. Guidelines for treatment of atopic eczema (atopic dermatitis) Part II. J Eur Acad Dermatol Venereol 2012; 26:1176-1193.

42. Wood RA, Kim JS, Lindblad R, et al. A randomized, double-blind, placebo-controlled study of omalizumab combined with oral immunotherapy for the treatment of cow's milk allergy. J Allergy Clin Immunol 2016; 137: 1103-1110.

43. Ciprandi G, Marseglia GL, Castagnoli R, et al. From IgE to clinical trials of allergic rhinitis. Expert Rev Clin Immunol 2015; 11:1321-1333.

44. Pitt TJ, Cisneros N, Kalicinsky C, et al. Successful treatment of idiopathic anaphylaxis in an adolescent. J Allergy Clin Immunol 2010; 126:415-416.

45. Hughes JDM, Olynyc T, Chapdelane H, et al. Effective management of severe cutaneous mastocytosis in young children with omalizumab. Clin Exp Dermatol 2018; 43:573-576.

46. Gauvreau GM, Arm JP, Boulet LP, et al. Efficacy and safety of multiple doses of QGE031 (ligelizumab) versus omalizumab and placebo in inhibiting allergen-induced early asthmatic responses. J Allergy Clin Immunol 2016; 138:1051-1059.

47. Kocaturk E, Maurer M, Metz M, et al. Looking forward to new targeted treatments for chronic spontaneous urticaria. Clin Transl Allergy 2017; 7:1.

48. Ortega HG, Liu MC, Pavord ID, et al. Mepolizumab treatment in patients with severe eosinophilic asthma. N Engl J Med 2014; 371:1198-1207.

49. Bel EH, Wenzel SE, Thompson PJ, et al. Oral glucocorticoid-sparing effect of mepolizumab in eosinophilic asthma. N Engl J Med 2014; 371:1189-1197.

50. Pavord ID, Korn S, Howarth P, et al. Mepolizumab for severe eosinophilic asthma (DREAM): a multicentre, double-blind, placebo-controlled trial. Lancet 2012; 380: 651-659.

51. Flood-Page P, Swenson C, Faiferman I, et al. A study to evaluate safety and efficacy of mepolizuab in patients with moderate persistent asthma. Am J Respir Crit Care Med 2007; 176:1062-1071.

52. Anderson WC, Szefler SJ. New and future strategies to improve asthma control in children. J Allergy Clin Immunol 2015; 136:848-859.

53. www.fda.gov/Drugs/InformationOnDrugs/ucm516834.htm

54. Raissy H, Blake K. Adolescent asthma pharmacotherapy in a state of flux. Pediatr Allergy Immunol Pulmonol 2015; 28:187-190.

55. Fala L. Nucala (mepolizumab): first IL-5 antagonist monoclonal antibody FDA approved for maintenance treatment of patients with severe asthma. Am Health Drug Benefits 2016; 9:106-110.

56. Wechsler ME, Akuthota P, Jayne D, et al. Mepolizumab or placebo for eosinophilic granulomatosis with polyangiitis. N Engl J Med 2017; 376:1921-1932.

57. Shahlavi-Monovvar P, Mobasher-Jannat A. Mepolizumab for eosinophilic COPD. N Engl J Med 2018; 378:681.

58. Tuttle KL, Buchheit KM, Laidlaw TM, et al. A retrospective analysis of mepolizumab in subjects with aspirin-exacerbated respiratory disease. J Allergy Clin Immunol Pract 2018; 6: 1045-1047.

59. Tsetsos N, Goudakos JK, Daskalakis D, et al. Monoclonal antibodies for the treatment of chronic rhinosinusitis with nasal polyposis: a systematic review. Rhinology 2018; 56 : 11-21.

60. Gotlib J. World Health Organization-defined eosinophilic disorders: 2017 update on diagnosis, risk stratification, and management. Am J Hematol 2017; 92:1243-1259.

61. Otani IM, Anikumar AA, Newbury Ro, et al. Anti-IL-5 therapy reduces mast cell and IL-9 cell numbers in pediatric patients with eosinophilic esophagitis. J Allergy Clin Immunol 2013; 131:1576-1582.

62. Bjermer L, Lemiere C, Maspero J, et al. Reslizumab for inadequately controlled asthma with elevated blood eosinophil levels: a randomized phase 3 study. Chest 2016; 150: 789-798.

63. Castro M, Zangrilli J, Wechsler ME, et al. Reslizumab for inadequately controlled asthma with elevated blood eosinophil counts: results from two multicenter, parallel, doubleblind, randomized, placebo-controlled, phase 3 trials. Lancet Respir Med 2015; 3:355-366.

64. Li J, Wang F, Lin C, et al. The efficacy and safety of reslizumab for inadequately controlled asthma with elevated blood eosinophil count: a systematic review and meta-analysis. J Asthma 2017; 54:300-307.

65. Corren J, Weinstein S, Janka L, et al. Phase 3 study of reslizumab in patients with poorly controlled asthma: effects across a broad range of eosinophil counts. Chest 2016; 150:799-810.

66. Hom S, Pisano M. Reslizumab (Cinqair): an interleukin-5 antagonist for severe asthma of the eosinophilic phenotype. PT 2017; 42:564-568.

67. Markowitz JE, Jobe L, Miller M, et al. Safety and efficacy of reslizumab for children and adolescents with eosinophilic esophagitis treated over nine years. J Pediatr Gastroenterol Nutr 2017; 66:893-897.

68. Bleecker ER, Fitzgerald JM, Chanez P, et al. Efficacy and safety of benralizumab for patients with severe asthma uncontrolled with high-dose inhaled corticosteroids and long-acting B2-agonists (SIROCCO): a randomized, mul- 
ticenter, placebo-controlled phase 3 trial. Lancet 2016; 388: 2115-2127.

69. FitzGerald JM, Bleecker ER, Nair P, et al. Benralizumab, an anti-interleukin-5 receptor alpha monoclonal antibody, as add-on treatment for patients with severe, uncontrolled, eosinophilic asthma (CALIMA): a randomized, doubleblind, placebo-controlled phase 3 trial. Lancet 2016; 388: 2128-2141.

70. Nowak RM, Parker JM, Silerman RA, et al. A randomized trial of benralizumab, an antiinterleukin 5 receptor alpha monoclonal antibody, after acute asthma. Am J Emerg Med 2015; 33:14-20.

71. Nair P, Wenzel S, Rabe KF, et al. Oral glucocorticoidsparing effect of benralizumab in severe asthma. N Engl J Med 2017; 376:2448-2458.

72. Castro M, Wenzel SE, Bleecker ER, et al. Benralizumab, an anti-interleukin 5 receptor alpha monoclonal antibody, versus placebo for uncontrolled eosinophilic asthma: a phase $2 \mathrm{~b}$ randomized dose-ranging study. Lancet Respir Med 2014; 2:879-890.

73. Goldman M, Hirsch I, Zangrilli JG, et al. The association between blood eosinophil count and benralizumab efficacy for patients with severe, uncontrolled asthma: subanalyses of the Phase III SIROCCO and CALIMA studies. Curr Med Res Opin 2017; 33:1605-1613.

74. FitzGerald JM, Bleecker ER, Menzies-Gow A, et al. Predictors of enhanced response with benralizumab for patients with severe asthma: pooled analysis of the SIROCCO and CALIMA studies. Lancet Respir Med 2018; 1:51-64.

75. Wenzel S, Ford L, Pearlman D, et al. Dupilumab in persistent asthma with elevated eosinophil levels. N Engl J Med 2013; 368:2455-2466.

76. Rabe KF, Nair P, Brusselle G, et al. Efficacy and safety of dupilumab in glucocorticoid-dependent severe asthma. $\mathrm{N}$ Engl J Med 2018; 378:2475-2485.

77. Castro M, Corren J, Pavord ID, et al. Dupilumab efficacy and safety in moderate-to-severe uncontrolled asthma. N Engl J Med 2018; 378:2486-2496.

78. Wenzel S, Catro M, Corren J, et al. Dupilumab efficacy and safety in adults with uncontrolled persistent asthma despite use of medium-to-high-dose inhaled corticosteroids plus a long-acting B2 agonist: a randomised double-blind placebo-controlled pivotal phase $2 \mathrm{~b}$ dose-ranging trial. Lancet 2016; 388:31-44.

79. Chung KF. Dupilumab: a potential new treatment for severe asthma. Lancet 2016; 388:3-4.

80. Eshtiangi P, Gooderham MJ. Dupilumab: an evidencebased review of its potential in the treatment of atopic dermatitis. Core Evid 2018; 13:13-20.

81. Wang FP, Tang XJ, Wei CQ, et al. Dupilumab treatment in moderate-to-severe atopic dermatitis: a systematic review and meta-analysis. J Dermatol Sci 2018; 90:190-198.

82. Corren J, Lemanske RF, Hanania NA, et al. Lebrikizumab treatment in adults with asthma. N Engl J Med 2011; 365: 1088-1098.

83. Noonan M, Korenblat P, Mosesova S, et al. Dose-ranging study of lebrikizumab in asthmatic patients not receiving inhaled steroids. J Allergy Clin Immunol 2013; 132:567574.

84. Hanania NA, Noonan M, Corren J, et al. Lebrikizumab in moderate-to-severe asthma: pooled data from two randomised placebo-controlled studies. Thorax 2015; 70:748-756.
85. Hanania NA, Korenblat P, Chapman KR, et al. Efficacy and safety of lebrikizumab in patients with uncontrolled asthma (LAVOLTA I and LAVOLTA II): replicate, phase 3, randomised, double-blind, placebo-controlled trials. Lancet Respir Med 2016; 4:781-796.

86. Simpson EL, Florh C, Eichenfield LF, et al. Efficacy and safety of lebrikizumab (an anti-IL-13 monoclonal antibody) in adults with moderate-to-severe atopic dermatitis inadequately controlled by topical corticosteroids: a randomized, placebo-controlled phase II trial (TREBLE). J Am Acad Dermatol 2018; 78:863-871.

87. Piper E, Brightlig C, Niven R, et al. A phase II placebocontrolled study of tralokinumab in moderate-to-severe asthma. Eur Respir J 2013; 4:330-338.

88. Brightling CE, Chanez P, Leigh R, et al. Efficacy and safety of tralokinumab in patients with severe uncontrolled asthma: a randomized, double-blind, placebo-controlled phase 2b trial. Lancet Respir Med 2015; 3:692-701.

89. Erpenbeck VJ, Popov TA, Miller D, et al. The oral CRTh2 antagonist QAW039 (fevipiprant): a phase II study in uncontrolled allergic asthma. Pulm Pharmacol Ther 2016; 39: 54-63.

90. Gonem S, Berair R, Singapuri A, et al. Fevipiprant, a prostaglandin D2 receptor 2 antagonist, in patients with persistent eosinophilic asthma: a single-centre, randomised, double-blind, parallel-group, placebo-controlled trial. Lancet Resp Med 2016; 4:699-707.

91. Gauvreau GM, O'Byrne PM, Boulet LP, et al. Effects of an anti-TSLP antibody on allergen-induced asthmatic responses. N Engl J Med 2014; 370:2102-2110.

92. Corren J, Parnes JR, Wang L, et al Tezepelumab in adults with uncontrolled asthma. N Engl J Med 2017; 377:936946.

93. Expert panel report 3: guidelines for the diagnosis and management of asthma. Bethesda, Maryland: National Institutes of Health, National Asthma Education and Prevention Program; 2007. NIH Publication No. 08-4051. www.nhlbi.nih.gov guidelines/asthma/asthgdln.pdf

94. GINA 217 update: http://ginasthma.org/2017-gina-reportglobal-strategy-for-asthma-management-and-prevention

95. Larsen GL. Differences between adult and childhood asthma. J Allergy Clin Immunol 2000; 106:S153-S157.

96. Drazen JM, Harrington D. New biologics for asthma. N Engl J Med 2018; 378:2533-2534.

Address correspondence to:
Elissa Abrams, MD, FRCPC
Section of Allergy and Clinical Immunology
Department of Pediatrics
University of Manitoba
FE125-685 William Avenue
Winnipeg R3E $0 Z 2$
Manitoba
Canada

E-mail: elissa.abrams@gmail.com

Received for publication March 29, 2018; accepted after revision July 26, 2018. 